\title{
Viral Strain-Specific Differential Alterations in Arabidopsis Developmental Patterns
}

\author{
Flora Sánchez, ${ }^{1}$ Pilar Manrique, ${ }^{1}$ Carmen Mansilla, ${ }^{1}$ Pablo Lunello, ${ }^{1}$ Xiaowu Wang, ${ }^{1}$ \\ Guillermo Rodrigo, ${ }^{2}$ Silvia López-González, ${ }^{1}$ Carol Jenner, ${ }^{3}$ Pablo González-Melendi, ${ }^{1}$ \\ Santiago F. Elena, ${ }^{2,4}$ John Walsh, ${ }^{3}$ and Fernando Ponz ${ }^{1}$ \\ ${ }^{1}$ Centro de Biotecnología y Genómica de Plantas (CBGP, UPM-INIA), Pozuelo de Alarcón, Madrid, Spain; ${ }^{2}$ Instituto de Biología \\ Molecular y Celular de Plantas, CSIC-UPV, Valencia, Spain; ${ }^{3}$ University of Warwick, Wellesbourne, Warwick, U.K.; and \\ ${ }^{4}$ The Santa Fe Institute, Santa Fe, New Mexico, U.S.A.
}

Submitted 21 May 2015. Accepted 3 September 2015.

\begin{abstract}
Turnip mosaic virus (TuMV) infections affect many Arabidopsis developmental traits. This paper analyzes, at different levels, the development-related differential alterations induced by different strains of TuMV, represented by isolates UK 1 and JPN 1. The genomic sequence of JPN 1 TuMV isolate revealed highest divergence in the $P 1$ and $P 3$ viral cistrons, upon comparison with the UK 1 sequence. Infectious viral chimeras covering the whole viral genome uncovered the $P 3$ cistron as a major viral determinant of development alterations, excluding the involvement of the PIPO open reading frame. However, constitutive transgenic expression of $\mathrm{P3}$ in Arabidopsis did not induce developmental alterations nor modulate the strong effects induced by the transgenic RNA silencing suppressor HC-Pro from either strain. This highlights the importance of studying viral determinants within the context of actual viral infections. Transcriptomic and interactomic analyses at different stages of plant development revealed large differences in the number of genes affected by the different infections at medium infection times but no significant differences at very early times. Biological functions affected by UK 1 (the most severe strain) included mainly stress response and transport. Most cellular components affected cell-wall transport or metabolism. Hubs in the interactome were affected upon infection.
\end{abstract}

Virus infections often cause diseases in plants. They are often systemic and, when thus, they cause the most damaging symptoms. The symptoms of such infections have been the subject of many descriptive and (fewer) mechanistic studies, due to their direct impact on yield and quality of agricultural products (Pallás and García 2011). However, viruses can also severely subvert

Current address for P. Manrique: Department of Microbiology and Immunology, Montana State University, Bozeman, MT, U.S.A.

Current address for P. Lunello: Agrenvec S. L., Tres Cantos, Madrid, Spain.

Current address for X. Wang: Institute of Vegetable and Flowers, Chinese Academy of Agricultural Sciences, Beijing, China.

Corresponding author: F. Ponz; E-mail: fponz@inia.es

*The $e$-Xtra logo stands for "electronic extra" and indicates that four supplementary figures, two supplementary datasets, and two supplementary tables are published online.

(C) 2015 The American Phytopathological Society plant development. This aspect of viral infections has received little attention, resulting in the potential for exploiting viruses for the study of development being underestimated, a surprising oversight. The obligate intracellular parasitic nature of viruses and their role as pirates of established processes in plants have been invaluable in the study of fundamental physiological phenomena, such as macromolecular intercellular movement (Lough and Lucas 2006) and gene silencing and its suppression (Csorba et al. 2015), to cite just two of the most relevant ones.

The relationship between virus infections and plant development has long been recognized. Years ago the concept of 'developmental resistance' was put forward, linking virus susceptibility of a given plant organ and its developmental stage (Leisner et al. 1993). The intimacy of this relationship is not fully understood; however, the major changes in the plasmodesmata pattern that occur during the sink-source transition (Oparka et al. 1999) may play an important role. Previously, we described a close relationship between the period of flower bud formation in Arabidopsis thaliana and RNA virus accumulation patterns in roots and systemically infected leaves (Lunello et al. 2007). The effect of virus infections in altering plant development has been indirectly approached through studying the effects of infections on hormones. Hormones mainly connected with pathogen responses have received the most attention in this area (Bari and Jones 2009). Fewer studies are available on the interplay between virus infection and developmental hormones, although such a connection has been made (Pallás and García 2011). The best-studied relationship between virus infections and alterations in plant development has been on the effect of the infections on the metabolism of small RNAs (sRNAs), especially micro RNAs (miRNAs), mediated by virus suppressors of RNA silencing (VSRs). This was first proposed about a decade ago (Kasschau et al. 2003) and has been shown for many viruses and many types of VSRs since (Csorba et al. 2015). However, the direct effect of VSRs on sRNAs does not account for all major effects on development. Thus, transgenic plants have been obtained in which growth and developmental defects caused by the potyvirus VSR HC-Pro have been corrected without affecting its ability to sequester sRNAs (Mlotshwa et al. 2005). Additionally, an ethylene-inducible transcription factor, RAV2, has been proposed as a major player in the silencing suppression induced by at least two different VSRs (Endres et al. 2010). Moreover, transgenic expression of two viral proteins with no recognized VSR activity, the movement and coat proteins (MP and CP, respectively) of Tobacco mosaic virus, interfered 
with miRNA metabolism (Bazzini et al. 2007) and had a major impact on the profile of plant gene expression (Conti et al. 2012).

Arabidopsis is a convenient host for host-virus interaction studies, resulting in an increase of research using viruses able to infect this plant. Among these, Turnip mosaic virus (TuMV; genus Potyvirus, family Potyviridae) was identified as a suitable pathogen many years ago (Martín Martín et al. 1999). Subsequently, this pathosystem has been widely used (Walsh and Jenner 2002). Since 2002, many studies have exploited the system for the investigation of a wide range of interactions, but the pathosystem has not been reviewed recently. TuMV infectious clones (Sánchez et al. 1998) and vectors expressing reporter proteins (Touriño et al. 2008) have been exploited in these studies.

Although most frequently infecting plants within family Brassicaceae, TuMV is able to infect hundreds of hosts in several families (Walsh and Jenner 2002). This is unusual for potyviruses, a genus whose members are typically characterized by narrow host ranges (Hollings and Brunt 1981). The reasons for this wide host range are not totally clear; it may be related to the high degree of genetic variability in TuMV. Several analyses of TuMV diversity have proposed a number of distinct viral strains, including recombinants (Ohshima et al. 2002; Sánchez et al. 2003, 2007; Tomimura et al. 2003). In our previous research, two strains (MB and MR) stood out as major ones. These strains contain isolates mostly infecting brassicas (MB) or radish (MR). Isolates UK 1 and JPN 1 (Jenner and Walsh 1996), respectively, are representative of these two TuMV strains. All TuMV-Arabidopsis interaction studies published so far have concentrated on UK 1 or related $\mathrm{MB}$ isolates, giving the misleading impression of a uniform response of the model plant to TuMV infection. In the present paper, we report a detailed comparison of symptomatology between UK 1 and JPN 1 infections of Arabidopsis, the identification of a major viral determinant and plant cellular and molecular mechanism underlying differential responses, with special emphasis on development-related symptoms. A brief advance in this area has been published recently, mostly discussing the differential induction of senescence by two TuMV strains (Manacorda et al. 2013).

\section{RESULTS}

\section{Representative isolates of two different TuMV strains alter the developmental plan of Arabidopsis in different ways.}

TuMV UK 1 and JPN 1 were inoculated to A. thaliana Col-0 under controlled environmental conditions. Inoculations were performed at developmental stage 1.08 (Boyes et al. 2001). Symptoms of infection started to become visible approximately 5 days postinoculation (dpi) (Sánchez et al. 1998). They were observed continuously and recorded. Infection phenotypes soon started to differ between strains. Table 1 summarizes the main features of the infection patterns, emphasizing developmental differences.

Some slight differences were observed in systemically infected leaves. Typical vein clearing was obvious in plants infected with either strain, although slightly more intense with JPN 1 (Supplementary Fig. S1). The vein clearing followed the classically described pattern of virus movement from source to sink leaves. Most JPN 1-infected leaves showed warped edges.

A major difference was evident at the stage of bolting and flower bud formation. A striking characteristic of UK 1-infected plants was that most of them failed to develop a flower stalk (Fig. 1). The small proportion of plants developing stalks generated very short and hooked ones, with no flowers or just a few that were mostly sterile. A different pattern was visible in JPN 1-infected plants. A time-course representation (Fig. 2) of virusinfected and control plants revealed arrested flower stalk growth in UK 1 but a different growth habit in JPN 1-infected plants, in which flower stalks were produced. Uninfected control plants exhibited a typical sigmoidal growth pattern, whereas the growth in JPN 1-infected plants showed a biphasic pattern. Both these patterns had a first phase consisting of almost perfectly linear growth with a smaller slope in JPN 1-infected plants. The slope change to the second phase occurred at approximately day 50 . JPN 1-infected plants kept growing almost indefinitely until the experiments ended when the plants senesced. They were consistently shorter than equivalent buffer-inoculated plants. Another clear difference was stalk morphology. Flower stalks in JPN 1-infected plants tended to creep, deviating notably from the normal erect configuration in control plants (Fig. 1).

Branching patterns were also quite different. Apical dominance in Col-0 allows clear differentiation of main and the shorter secondary and tertiary branches. Apical dominance was lost in JPN 1-infected plants (this trait could not be analyzed in UK 1-infected plants, due to the lack of stalks). The consequence was the formation of multibranched plants with extraordinary long secondary and tertiary branches (Fig. 1). These creeping stalks and branches were fragile and easily broken when manipulated. When inspected closely, other characteristics of JPN 1-infected branches were evident. A curious one was the tendency of branches to form at a 90-degree angle with the stalk. In many cases, the junction was blackened, possibly due to over-lignification. Internodes were quite irregular in length. Occasionally, the direction of growth of secondary branches was diverted in the opposite direction. The length of such branches was very short, their stalks were twisted, and the developing flowers formed a compact bunch.

Flower development was also differentially affected (Fig. 3). As mentioned above, few flowers could be analyzed in UK 1 -infected plants despite many inoculation experiments, as they were abnormal and mostly nonfertile. Individual sepals and petals were very separated from each other. The flowers also had stunted stamens, immature anthers, and very few produced pollen grains. Those that did produce pollen produced very little relative to control plants. In contrast, JPN 1-infected plants produced flowers, many of which appeared fertile. Their petals and sepals also had a tendency to be separated and their stamens were slightly shorter than in control plants. However, pollen production was almost normal and viable seeds were

Table 1. The main developmental traits affected by Turnip mosaic virus (TuMV) infection

\begin{tabular}{|c|c|c|}
\hline $\begin{array}{l}\text { Plant } \\
\text { organ }\end{array}$ & TuMV UK $1^{\text {a }}$ & TuMV JPN 1 \\
\hline Leaf & Light vein clearing & Intense vein clearing \\
\hline \multirow{7}{*}{$\begin{array}{l}\text { Flower } \\
\text { stalk }\end{array}$} & Arrested elongation & Lineal growth \\
\hline & Hooked stem* & Hooked stem \\
\hline & & Shorter than control (28 dai) \\
\hline & & Creeping \\
\hline & & Increased thickness \\
\hline & & Fragile \\
\hline & & $\begin{array}{l}\text { Altered branching pattern (internode } \\
\text { length, node differentiation, } \\
\text { blackened secondary stems at an } \\
\text { angle of } 90^{\circ} \text { to the main stem) }\end{array}$ \\
\hline \multirow[t]{4}{*}{ Flower } & Infertile* & Fertile \\
\hline & Separated petals* & Separated petals \\
\hline & Separated sepals* & Separated sepals \\
\hline & $\begin{array}{l}\text { Very stunted stamens* } \\
\text { Immature anthers* }\end{array}$ & Shorter stamens \\
\hline Root & Arrested root growth & $\begin{array}{l}\text { Main root shorter than control } \\
\text { Secondary root proliferation }\end{array}$ \\
\hline
\end{tabular}

${ }^{a}$ Asterisks (*) indicate traits rarely observed, only when flower stalk elongated enough to produce some flowers. 
easily recovered. Occasionally some rare developmental defects were seen in JPN 1-infected flowers.

Alterations in infected roots were reminiscent of the differential changes above ground. Thus, the main root in UK 1 -infected plants was much shorter than controls and secondary roots developed to a significantly lesser extent. In contrast, root proliferation was exacerbated in JPN 1-infected plants.
We tried to influence symptom development through the action of externally added hormones. Specifically, we treated virus-inoculated and control plants five times every $48 \mathrm{~h}$ separately with two auxins (1-naphthaleneacetic acid and 2,4dichlorophenoxyacetic acid), giberellin GA3, or an inhibitor of polar auxin transport naphthylphthalamic acid, in two treatments, starting $6 \mathrm{~h}$ postinoculation or $3 \mathrm{dpi}$. No clear visible
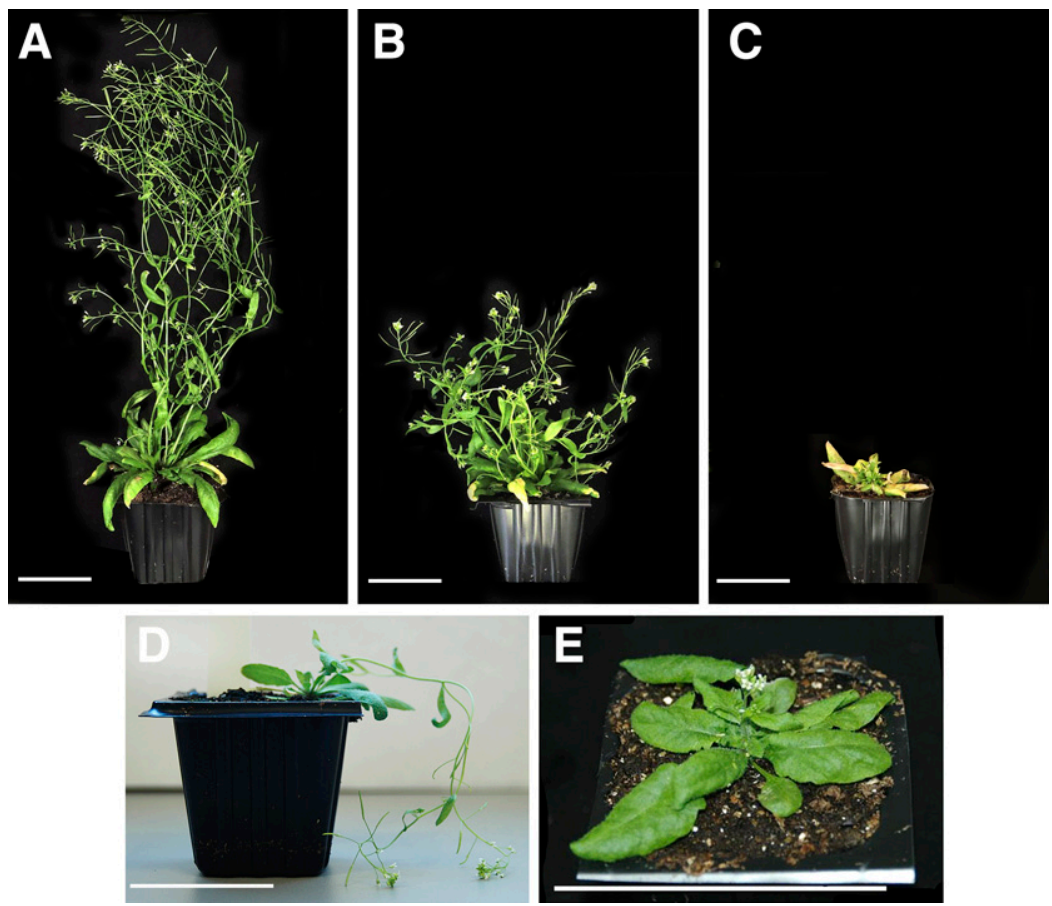

Fig. 1. Effects of different Turnip mosaic virus strains on Arabidopsis Col-0 development. A, Comparison of buffer-inoculated, B, JPN 1-infected, and C, UK 1-infected plants. For better size and global architecture comparisons, pictures were taken with pots leaning to one side and plants were placed not to show creeping effects. D, a JPN 1-infected plant showing the induced creeping effect. E, A close-up of a UK 1-infected plant showing an extremely short flower stalk and flowers forming a bunch. $\mathrm{Bar}=5 \mathrm{~cm}$.

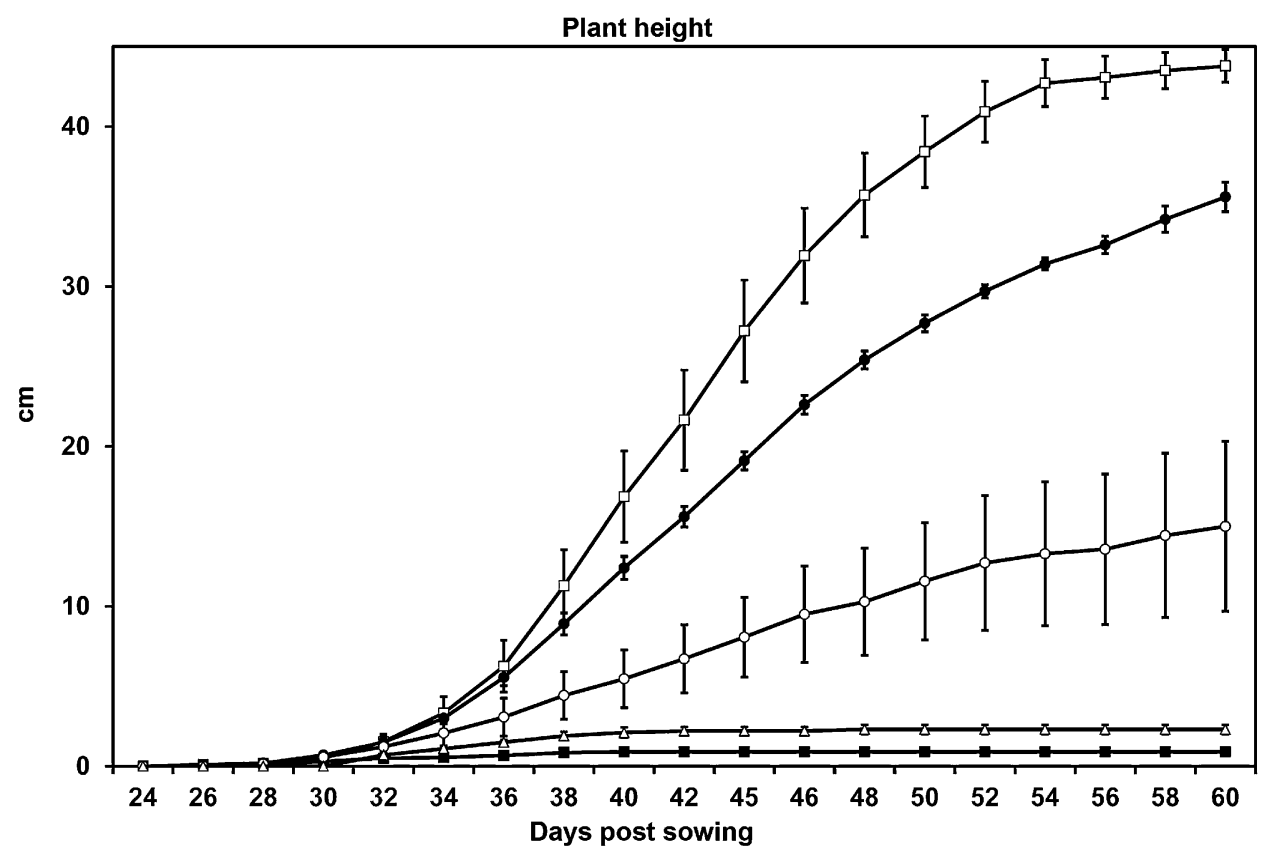

Fig. 2. Flower-stalk growth curves. Values represent averages of 6 to 14 plants per inoculum. UK 1 and JPN 1 represent wild-type Turnip mosaic virus inoculations. Ch. represent plants inoculated with chimeric viruses. Inoculation at 21 days post sowing, always before developmental stage 5 . Open squares represent buffer-inoculated plants; filled squares, UK 1; filled circles, JPN 1; open circles, Ch.U(2511-3767)J; and triangles, Ch. J(2511-3767)U. Standard errors are shown. 
changes in the symptoms induced were observed following these hormone treatments. No treatment reversed dwarfism or inhibition of stalk development of UK 1-infected plants. A very slight increment in size and growth rate was observed in JPN 1 -infected plants in response to GA3 in the treatment starting 3 dpi but not in the earlier treatment.

A simple potential explanation for differences observed between UK 1 and JPN 1 infections could be based on viral titers reached by the different strains. We have already reported on this comparative analysis between strains (Manacorda et al. 2013). With the exception of a slight delay in the movement of JPN 1 relative to UK 1, no major differences were found.

\section{TuMV UK 1 severely impacts cell spatial distribution} in the developing vascular bundle.

Prevention of stalk elongation by UK 1 is a major factor affecting Arabidopsis development. Discovering the causes of this arrest, consequently, became a principal goal of our research in this area. A microscopic examination of stalk structure was undertaken. While both JPN 1- and UK 1-infected plants (Fig. 4) showed alterations in the organization of the vascular bundles relative to controls, the differences were more striking in UK 1-infected plants. Thus, UK 1 infection brought about ectopic cell-wall thickening within the vascular vessel and in the intervascular parenchyma. It is very likely that this ectopic alteration had an impact on stalk development.

\section{A major determinant of differential developmental alterations maps to a viral genomic region coding for a nonstructural protein.}

Mapping viral molecular determinants of the differential effects should shed light on possible underlying mechanisms. Normally this type of mapping work is approached by interchanging viral genomic segments of the differential isolates and looking for changes in the induced phenotypes. The genomic sequence of UK 1 had been published (Sánchez et al. 1998), but the sequence of JPN 1 was not available. A cDNA version of the JPN 1 RNA genome was cloned by assembling different amplified segments into a single full-length (FL) construct and sequencing. Analysis of the sequence revealed typical potyviral genomic organization.

When compared with the MB-type isolate UK 1, it was evident that JPN 1 is, indeed, an isolate of TuMV but belonging to a different strain, as we have already proposed based on restriction fragment length polymorphisms (Sánchez et al. 2003). A detailed comparative analysis is presented in Supplementary Data Set S1. The P3 was the most divergent cistron between both isolates in terms of amino acids.

In a similar manner to our previous work with UK 1, we assembled a FL cDNA version of JPN 1, with the aim of generating an infectious clone. The FL clone was resequenced to verify that no errors had been introduced. After repeated attempts to infect plants by rubbing DNA from this FL clone or by shooting it with a gene gun, no infection was obtained. This presented a major obstacle in the mapping effort and other approaches are currently being pursued in order to produce the JPN 1 infectious clone. Despite this problem, the mapping work was possible, as several of the chimeras between JPN 1 and UK 1 were infectious.

For initial coarse mapping of one or more viral genomic regions involved in the different symptom types, five chimeras were prepared, taking advantage of the position of common restriction enzyme recognition sites. These were chimeras Ch. U(1-605)J, Ch. U(606-2501)J, Ch. U(2511-3767)J, Ch. U(3768-5744)J, and Ch. U(5592-9834)J (the caption for Figure 5 provides details about the terminology used). All were made in the UK 1 FL clone template, as the JPN 1 FL was not infectious. The five consecutive chimeras cover the entire viral genome. DNA from the chimeric clones was prepared,
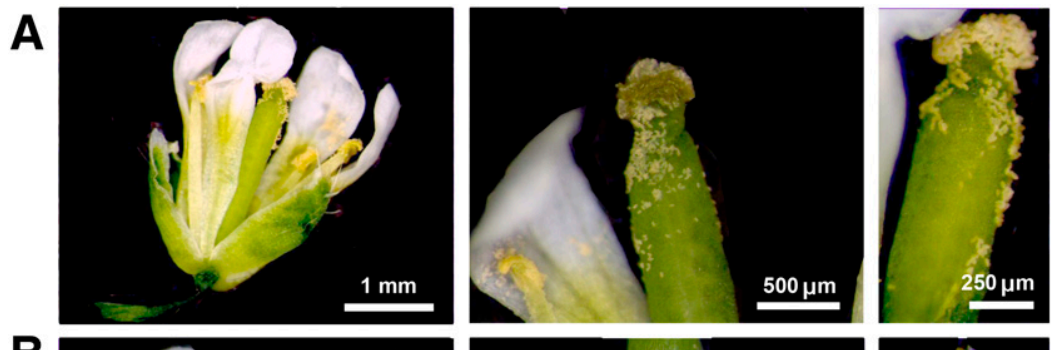

B
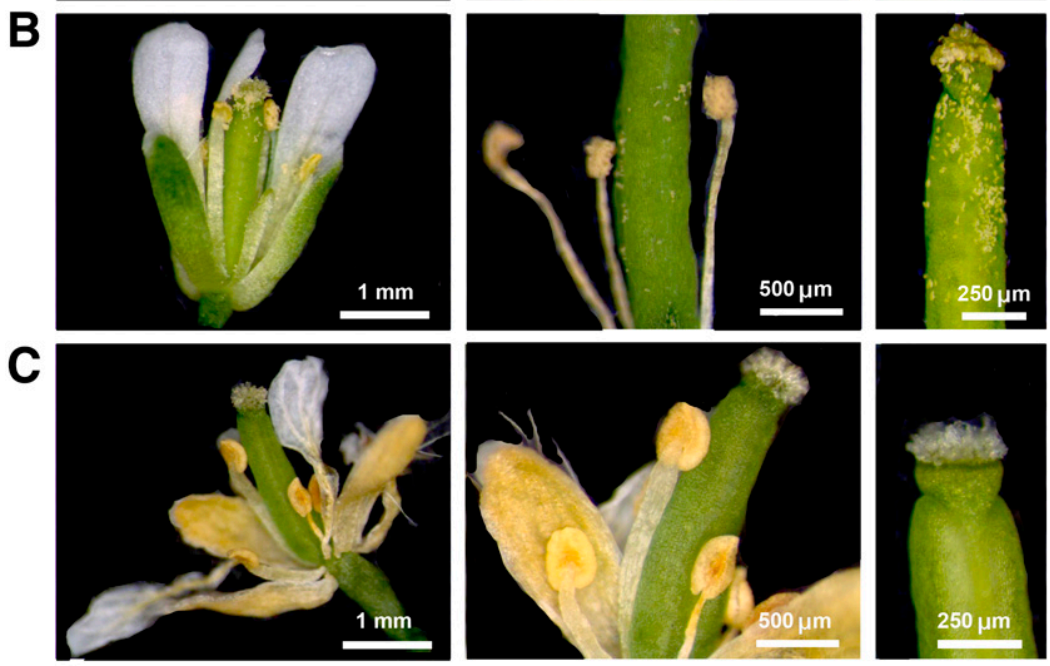

Fig. 3. Effects of Turnip mosaic virus infections on Arabidopsis flower development. A, Flower from a buffer-inoculated plant; B, from a JPN 1-infected plant; and $\mathbf{C}$, from a UK 1-infected plant. Pictures represent the most common phenotypes obtained, with flowers from JPN 1-infected plants having reduced pollen production and UK 1-infected plants producing no pollen. 
passaged in Arabidopsis (pass 0), and crude sap of infected plants was used as inoculum. Since chimeras were made on the UK 1 template, the trait to map in this case was the elongation of flower stalks. Of the five chimeras tested, only Ch. U(2511-3767)J infection permitted stalk elongation (Fig. 2, open circles), albeit shorter than those in JPN 1-infected plants. The result suggested that the ability to affect flower stalk elongation in TuMV-infected Arabidopsis is determined within a region comprising a few (26) codons from the HC-Pro C-terminal region, the entire P3 cistron (including the PIPO open reading frame [ORF]) and a few (37) codons from $6 \mathrm{~K} 1$. This result would be strengthened if the inverse chimera (swapping the UK 1 stretch onto the JPN 1 FL) would convert the stalk-elongating JPN 1 phenotype into a non-elongating UK 1 type. As the JPN 1 FL was not infectious, this experiment was theoretically not currently possible. However, the behavior of one parent should not necessarily dictate the behavior of the chimera, so chimera Ch. J(2511-3767)U was generated. This chimera turned out to be infectious in Arabidopsis and the infected plants did not develop a stalk (Fig. 2).

The results point to $\mathrm{P} 3$ as the main determinant, at least for stalk elongation. However, the new potyviral ORF PIPO (Chung et al. 2008) is completely embedded in the P3 ORF. To establish whether or not PIPO was involved in stalk elongation, we took advantage of the position of the SnaBI recognition site
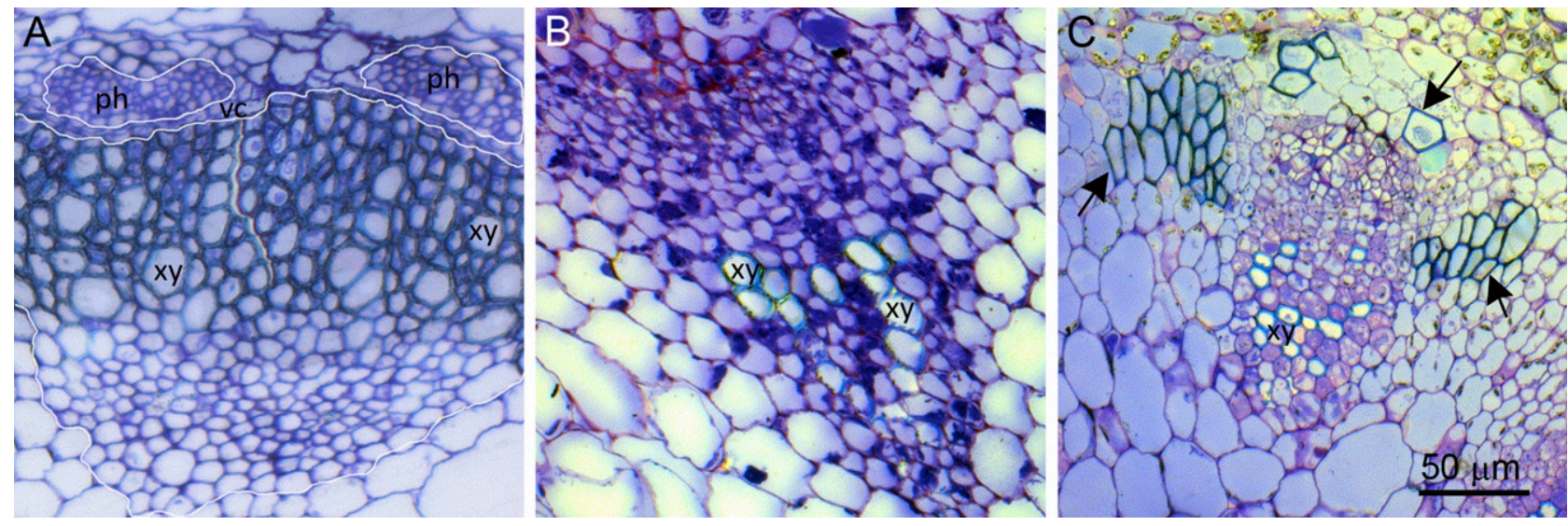

Fig. 4. Toluidine blue O-stained sections (1 to $2 \mu \mathrm{m}$ ) of early developing stalks observed under bright field. A, Control specimens show the typical organization of the vascular bundles. White lines contour the areas containing the phloem tissue (ph) and the lignified tracheary elements of the xylem (xy), located outward and inward, respectively, of the vascular cambium meristem (vc). B, In Turnip mosaic virus (TuMV) JPN 1- and C, TuMV UK 1-infected plants, the organization is altered. Xylem and phloem tissues are less defined and vascular vessels (xy) are less numerous and intermingled with parenchyma cells. UK 1 infection brought about a more striking effect, in that the few xylem vessels were thinner and ectopic cell-wall thickening within the intervascular parenchyma (arrows) was observed.

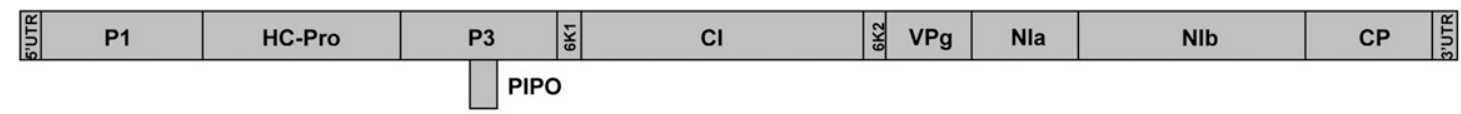

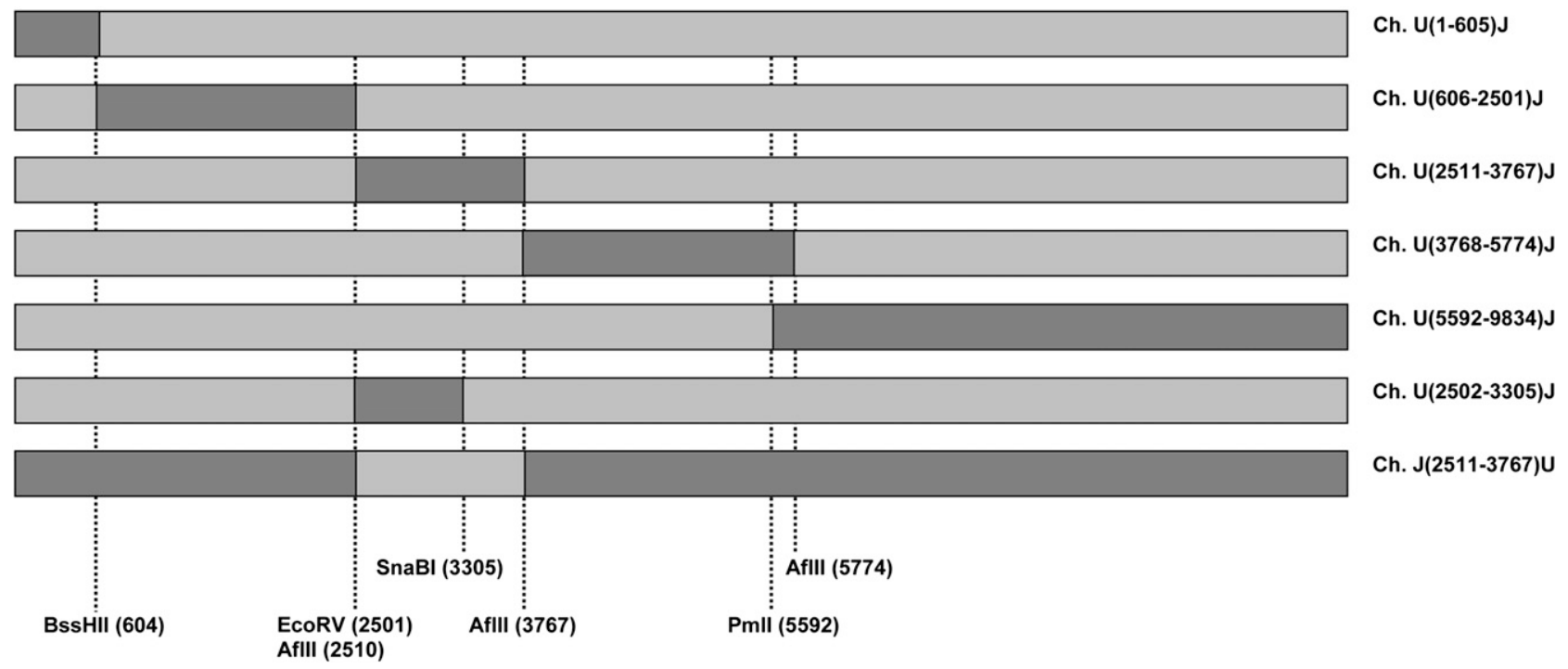

Fig. 5. Scheme of the genetic chimeras generated by DNA swapping between full-length (FL) cDNA clones of UK 1 and JPN 1 . The upper bar represents the cistron array of potyviruses within the viral main open reading frame (ORF). Embedded in it is the small ORF PIPO, within the P3 cistron. The remaining bars represent viral chimeras. Terminology: the first letter (U or J) denotes the template FL clone (UK 1 and JPN 1, respectively) on which the swapping was performed, numbers in parentheses represent the first and last nucleotide of the sequence interchanged, the last letter ( $U$ or $J$ ) represents the donor isolate of the interchanged DNA sequence. Light gray indicates the UK 1 sequence and dark gray the JPN 1 sequence. The restriction enzymes used for sequence interchange are shown under their corresponding position in the viral sequence. Note that the PIPO ORF falls completely within the EcoRV (2501) or AflII (2510) and SnaBI (3305) fragment. 
within P3. This enzyme cuts downstream of PIPO, allowing the generation of a subchimera splitting P3 into two pieces and leaving PIPO only in one of them [Ch. U(2502-3305)J]. Upon infection of Arabidopsis with this chimera, we established that the P3 subdomain involved in stalk elongation is within the codons downstream from the SnaBI site, as plants infected with this subchimera did not elongate a stalk. This shows that the ORF PIPO is not involved in stalk elongation.

\section{Nonreproducibility of differential viral symptoms by the constitutive expression of candidate viral genes in transgenic plants.}

Reproducing the differential effects in Arabidopsis in the absence of virus infection was attractive, as it would avoid the parallel processes caused by a replicating virus. This objective was investigated through transgenic expression of viral pathogenic determinants. In the case of potyviruses, the determinant most frequently used for this purpose has been the VSR HC-Pro, repeatedly shown to induce developmentrelated symptoms (Csorba et al. 2015). Considering this and our own results, we decided to generate simple and double transgenic Arabidopsis lines expressing one or both HC-Pro and P3 from UK 1 or JPN 1.

Constructs for four different transgenic lines were generated and were used to transform Arabidopsis Col-0. Control lines transformed with empty vector (EV) were already available in our laboratory (Mansilla et al. 2006). Several lines were obtained for each construct and one from each was chosen as a representative for further work. Transgenic progeny with single-locus insertions were identified by kanamycin-resistance segregation. Homozygosity was achieved by repeated selfing and selection until lines with no segregation for antibiotic resistance were identified. In the case of HC-Pro transgenic lines, this was more difficult, given the flower sterility mentioned above. However, some flowers were able to self-fertilize and produce siliques and seeds. Double-transgenic lines were generated by crossing HC-Pro and P3 transgenic lines. Crosses were made to generate lines carrying both transgenes from the same strain or one transgene from each strain (UU, JJ, UJ, and JU). Given the difficulty in obtaining fertile pollen from HC-Pro transgenic lines, we worked with crosses in which the pollen-donor lines were the P3 transgenic lines.

In single transgene lines, no phenotype differentiating EV and P3 lines was observed (Fig. 6). On the contrary, quite severe symptoms were displayed by HC-Pro lines, regardless of the strain of origin. These symptoms were globally reminiscent of a
UK 1 infection (Fig. 6), even in lines carrying JPN 1 HC-Pro. This type of very severe phenotype induced in TuMV HC-Pro transgenic Arabidopsis lines has also been reported by other groups (Kasschau et al. 2003; Chapman et al. 2004; Mlotshwa et al. 2005) but, so far, only for UK 1 or other MB isolates, as far as we are aware.

Double transgenic lines, heterozygous for both transgenes, did not significantly change the severe phenotype induced by HCPro expression. The expression of $\mathrm{P} 3$ in these double transgenic lines was confirmed by reverse transcription-polymerase chain reaction (RT-PCR). So, even though we identified P3 as a viral product playing a relevant role in the infection phenotype, its constitutive expression away from the highly regulated expression of a viral infection did not modulate the strong developmental effects of the constitutively expressed viral VSR.

\section{Transcriptomic and interactomic analyses} of the Arabidopsis genes differentially expressed following infection with the different TuMV strains.

To gain insights into the most relevant gene-expression changes underlying the differential alterations caused by the two viruses, we took a transcriptomic approach. Total RNA was isolated from aerial plant tissue above the virus-inoculated leaf and was subjected to microarray analysis. For the microarray analysis, we selected two different times (T1, T2) after virus inoculation, paying particular attention to the standardization of the developmental stage for each of the two selected times (Supplementary Fig. S2). These times were T1, 4 days after inoculation, and T2, 11 days after inoculation. Only the plants reaching developmental stage 5.1 at 22 days after sowing were included in the analysis.

The results obtained after the microarray hybridizations were normalized and differentially expressed genes were identified. These are shown for both strains in Supplementary Data Set S2. No statistically significant differences in gene expression were identified between control plants and plants infected with any TuMV-infecting strain at the early time point (T1). This result prevented a dynamic view of the infections. At T2, many significant changes were found. For UK 1-infected plants, 966 genes were upregulated and 330 were downregulated. Numbers for JPN 1 were 42 (up) and 22 (down). Altered genes shared by both strains were 23 (up) and 13 (down). A graphical representation of these numbers is presented in the form of a Venn diagram in Supplementary Figure S3. The validation of these microarray-based changes was performed by RT-quantitative (q)PCR on a small subset of selected genes (Supplementary Fig. S4).
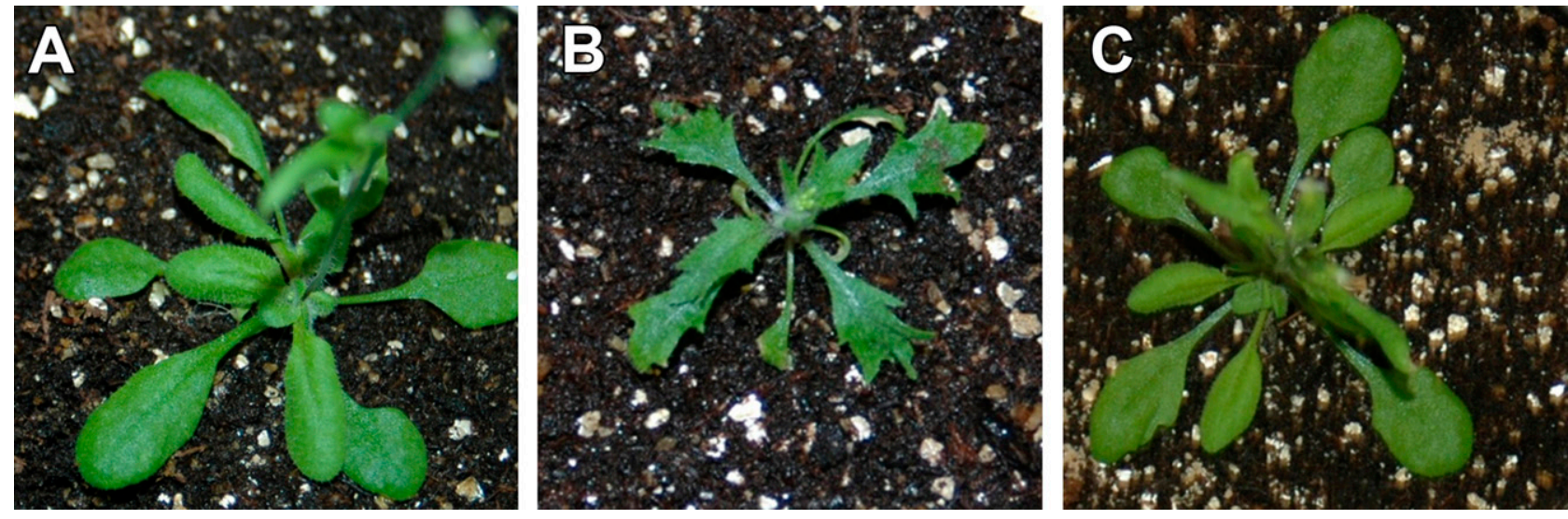

Fig. 6. Transgenic Arabidopsis plants homozygous for Turnip mosaic virus (TuMV) transgenes. A, Empty vector, a transformation control, B, HC-Pro, and C, P3. All TuMV genes derived from the JPN 1 isolate; equivalent UK 1 transgenic plants were practically indistinguishable. 
Altered genes were also subjected to analyses of biological functions and cellular components, from which significantly enriched gene ontology (GO) terms were identified. Figure 7 shows the results obtained for biological functions when UK 1 and JPN 1 were directly compared. This comparison uncovered mainly stress response and transport functions upregulated for UK 1 and metabolic, developmental, and gravitropic processes downregulated for this isolate. A similar analysis was performed for cellular components. These results are shown in Table 2. An inspection of the altered GO terms reveals a large number were related to cell-wall transport or metabolism and to plastid components.

A global picture of the effects of virus infection can be obtained if altered genes are examined from the point of view of the described interactions of their encoded proteins (Elena and Rodrigo 2012; Elena et al. 2011). In the case of Arabidopsis, such an interactome is available: the At-PPIN (Arabidopsis Interactome Mapping 2011), covering about 20\% of the total genes. Among the list of differentially expressed genes (overand underexpressed), only 174 were present in the $A t$-PPIN. We analyzed whether the differentially expressed genes were more connected, central, or clustered than expected by chance, but no significant results were seen following comparison with random lists of genes of the same length $(U$ test, $P>0.1)$. From the differentially expressed genes mapped in the At-PPIN, we selected those with the highest degree of difference (top five) and representing the resulting subnetwork (Fig. 8). The microarraybased differential expression of these five genes was validated by means of RT-qPCR analysis. These genes have a degree greater than 20 and could be considered as hubs in the At-PPIN, because the average degree of a given protein in the interactome is 4.94. In essence, we observed two different clusters of genes, one related to defense and stress response (mediated by MPK3, WRKY60, and TOE2) and another related to signaling and metabolic processes (mediated by CML4 and CML10). These two clusters have an interface with several common interactions (Fig. 8).

\section{DISCUSSION}

TuMV is an atypical potyvirus displaying quite a broad host range in comparison with most other virus species in the genus. To date, there is no clear single explanation for this peculiarity. Variability and evolutionary relationships of the virus have been researched intensively over the last decade or so, and suggestions of a high recombination rate or expansions of certain virus populations have been put forward (Nguyen et al. 2013; Ohshima et al. 2007). Whatever the underlying genetic reasons, many different isolates of the virus have been described and sequenced, which has allowed proposals of strain classifications. We proposed a classification of TuMV isolates into genetic strains based on genetic distances of their CP cistrons (Sánchez et al. 2003, 2007). Both in our proposal and those of others, an important criterion for grouping isolates was their ability to infect differential hosts. The isolates considered in this work, UK 1 and JPN 1, are isolates of different viral strains. In our classification, isolate UK 1 was a typical MB strain and JPN 1 an MR strain. The UK 1 isolate is mostly noninfectious in Raphanus spp. but JPN 1 is able to infect Brassica spp., although inducing only light symptoms. Thus, they represent genuine instances of host adaptation (Ohshima et al. 2010; Tan et al. 2005). Early in our studies on TuMV, we realized that this major classification of the virus strains reflected the type of symptoms induced in Arabidopsis, a common host for all TuMV isolates tested (Sánchez et al. 2003). We found that these two isolates alter plant development in very different ways, so we began an investigation of the underlying determinants and mechanisms of the differential developmental alterations from pathogen and host standpoints.

Table 2. Arabidopsis thaliana cellular component gene ontology (GO) terms differentially altered by Turnip mosaic virus isolates UK 1 and JPN 1

\begin{tabular}{|c|c|c|}
\hline GO term & Name & $\begin{array}{l}\text { Level of expression } \\
\text { (UK } 1 \text { versus JPN 1) }\end{array}$ \\
\hline GO:0005618 & Cell wall & Upregulated \\
\hline GO:0044431 & Golgi apparatus part & Upregulated \\
\hline GO:0009288 & Bacterial-type flagellum & Upregulated \\
\hline GO:0019861 & Flagellum & Upregulated \\
\hline GO:0000148 & $1,3-\beta$-D-glucan synthase complex & Upregulated \\
\hline GO:0031410 & Cytoplasmic vesicle & Upregulated \\
\hline GO:0031982 & Vesicle & Upregulated \\
\hline GO:0008287 & $\begin{array}{l}\text { Protein serine/threonine } \\
\text { phosphatase complex }\end{array}$ & Upregulated \\
\hline GO:0009579 & $\begin{array}{l}\text { Thylakoid, a membranous } \\
\text { cellular structure that bears the } \\
\text { photosynthetic pigments }\end{array}$ & Downregulated \\
\hline GO:0042651 & Thylakoid membrane & Downregulated \\
\hline GO:0009295 & Nucleoid & Downregulated \\
\hline
\end{tabular}

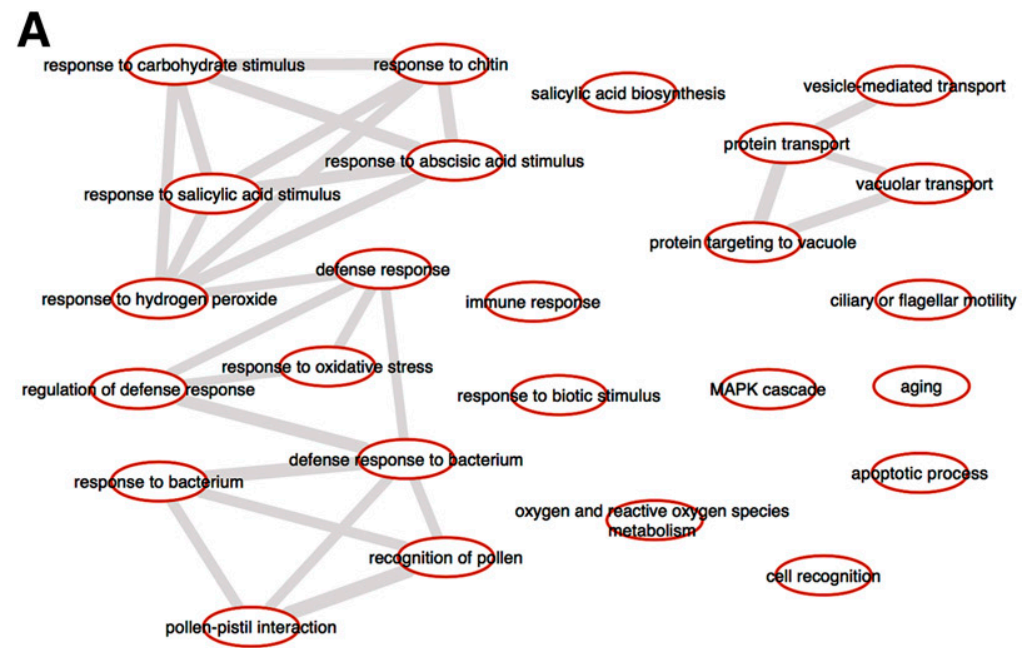

B

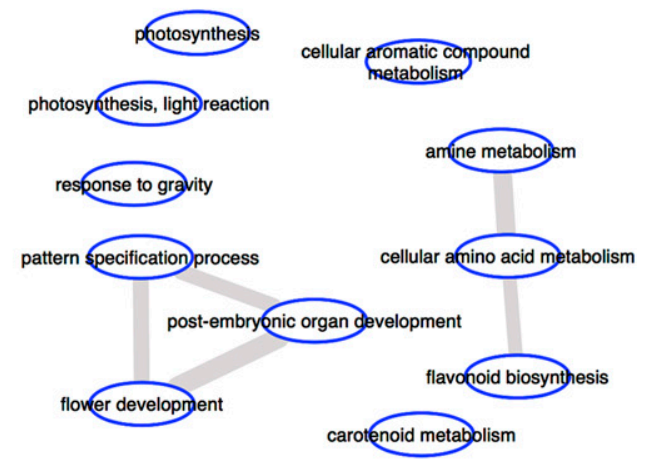

Fig. 7. Functional analysis of the differential infection of UK 1 versus JPN 1. The biological functions (gene ontology terms) overrepresented within lists A, of upregulated genes and B, of downregulated genes are shown. Representations obtained with REVIGO (Supek et al. 2011). 


\section{The viral component of the interaction.}

TuMV UK 1 whole-genome sequence was available (Jenner et al. 2000); however, the JPN 1 sequence had not been determined. This information was necessary for studies on the viral determinants of differential effects on Arabidopsis, so the isolate was sequenced. This revealed a typical TuMV MR strain, its closest relative being TuMV isolate 59J, also an MR isolate. Compared with the sequence of UK 1, the JPN 1 sequence revealed $\mathrm{P} 1$ and $\mathrm{P} 3$ as the most divergent regions at the amino acid level, in agreement with reported studies on TuMV taxonomy (Ohshima et al. 2007). As discussed later, the high degree of divergence in $\mathrm{P} 3$ is especially relevant in the context of our study.
Sequence information permitted viral determinant investigation through genomic exchanges utilizing the UK 1 infectious clone p35Tunos. Despite many attempts to generate a JPN 1 infectious clone, none were successful. Several FL clones, similar to p35Tunos, were generated, but either their ORF was interrupted by the insertion of nonviral sequences after clone cultivation in Escherichia coli or they simply did not induce an infection in the usual TuMV experimental hosts. To our knowledge, no TuMV-MR infectious clone has ever been reported, so this is still to be achieved. Nevertheless, we were able to pursue determinant identification, as we obtained infectivity based on JPN 1 sequence substitution of corresponding UK 1 fragments in candidate regions of p35Tunos.

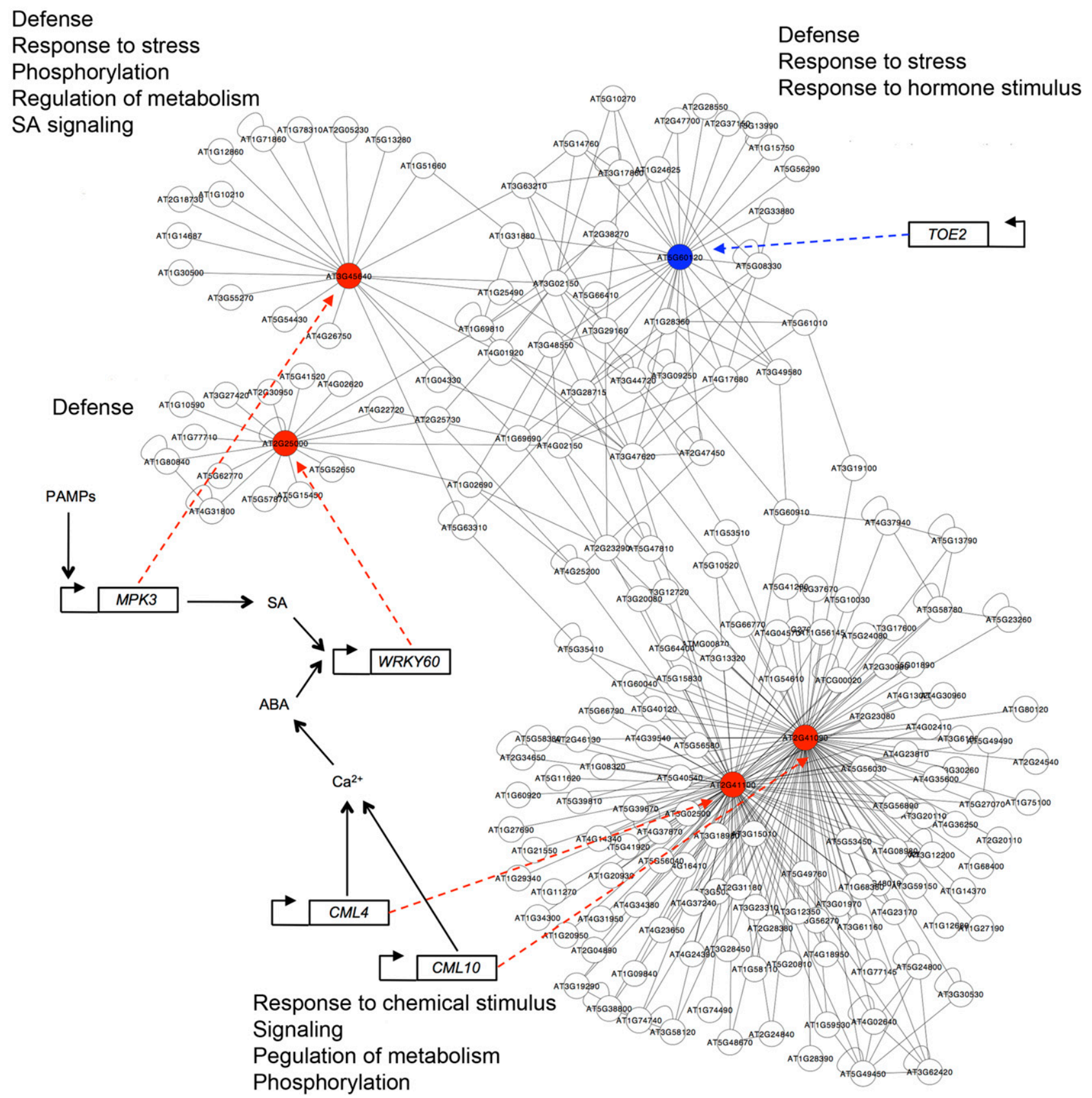

Fig. 8. Arabidopsis interactome subnetwork showing the interactions of the top five UK 1-altered genes with the highest connection degrees. Red nodes represent upregulated by UK 1 infection. The blue node is a downregulated gene. Names of the five central genes (nodes) are shown within boxes. Main gene ontology (GO) terms for the central genes in the networks are given adjacent to their networks. The interface between the two main clusters in the subnetwork is shown through arrows connecting intermediate cellular factors. 
The conclusion of this study was that the region around the P3 cistron is involved in affecting flower stalk elongation. This trait is important because most of the other traits (flower development, branching, and others) depend on it. Although the interchanged viral genomic fragment contained stretches from the HC-Pro and 6K1 cistrons, no differences in the deduced amino acid sequences between the interchanged HC-Pro stretches were identified, and there were only two conservative differences (valines to isoleucines) in $6 \mathrm{~K} 1$. More than $15 \%$ of the deduced P3 amino acid sequences are different between strains, making this the most likely candidate. The involvement of the newly discovered PIPO ORF was ruled out through the construction of the Ch. U(2502-3305)J chimera, which, when inoculated to Arabidopsis, resulted in plants not developing a stalk.

P3 seems to be a major determinant but not the only one. Plants infected by chimera Ch.U(2511-3767)J developed a flower stalk but its final length did not reach the values obtained in plants infected with wild-type JPN 1. Thus, it seems important for P3 is to be in the correct genomic context with one or more other parts of the viral genome, possibly indicating some form of interaction of P3 with one or more other homologous viral gene products. P3 is one of the least-characterized potyviral proteins. In the case of TuMV, the protein has been identified as a determinant for host resistance to the virus (Jenner et al. 2002, 2003; Kim et al. 2010) and has been implicated as a symptom and host range determinant (Jenner et al. 2003; Suehiro et al. 2004; Tan et al. 2005). Isolates used for these earlier studies have been $\mathrm{MB}$ in all cases. For other potyviruses, the same main characteristics have been identified for their P3 proteins. As far as we are aware, no other developmentally-related P3-induced differential symptomatologies have been considered, but our results indicate that these are strongly P3-influenced. Differential effects of P3 at the cellular and subcellular levels are likely to be the basis of the differential symptoms at the organism level, but the basis for proposing hypotheses along these lines is difficult. Some properties of the protein have been addressed in different potyviruses, but the picture is far from clear. There are reports of the localization of the protein in the endoplasmic reticulum and the Golgi apparatus (Cui et al. 2010; Eiamtanasate et al. 2007) but also in the nucleus (Langenberg and Zhang 1997; Zilian and Maiss 2011) and in the cytoplasm (Rodríguez-Cerezo et al. 1997). No specific study has been performed for TuMV P3 in this context, except for a description of the protein interacting with RubisCO, a property that seems to be general for this protein in several potyviruses (Lin et al. 2011). It would be worth exploring whether the protein dynamics, localization, or interactions with plant factors, singly or in combination, differ between MB and MR TuMV strains, a reasonable possibility given the differences in the protein at the sequence level.

Viral VSRs have long been identified as developmental modifiers (Csorba et al. 2015). Since no VSR role has been assigned to P3, we included the TuMV VSR HC-Pro in our symptom analysis following transgenic constitutive expression of individual viral proteins, an experimental approach widely used in this context (Csorba et al. 2015). To our knowledge, no transgenic plant expressing an MR HC-Pro has been reported. So, we generated homozygous single-insert Arabidopsis lines constitutively expressing P3 or HC-Pro from UK 1 or JPN 1. All HC-Pro transgenic lines exhibited a severe developmental phenotype, regardless of the isolate of origin, very similar to phenotypes already described for other transgenic lines using MB HC-Pro. This result disproved the hypothesis of HC-Pro being the major driver of the differential developmental alterations. None of the P3 transgenic lines showed visible developmental alterations, regardless of the strain of origin. Molecular analyses showed that this was not due to lack of transgenic expression. One possibility that could relate to all development-related aspects considered so far, was that some kind of epistatic effect of P3 over HC-Pro could be modulating the strong HC-Pro effects. Epistasis between alleles in different plant virus genes has already been documented (Lalić and Elena 2013). Observation of F1 plants from all possible crosses did not identify any effect of P3 on the phenotype imposed by HC-Pro. So, P3 seems to require the whole virus context to exert its effect on plant development. We cannot discard the possibility of P3 modulating the effect HC-Pro has on Arabidopsis development in the context of viral infection. A putative effect of P3 on HC-Pro would probably be indirect, since no direct interaction of P3 and HC-Pro has ever been found in TuMV or in any other potyvirus subject to this type of analysis. An exception to this could be the P3 of Wheat streak mosaic virus, not a true potyvirus but a tritimovirus in the Potyviridae family (Choi et al. 2000).

\section{The plant component of the interactions.}

Differential phenotypes induced by the two virus isolates representing different strains indicate that the physiological and molecular plant responses must be different. Our attempts to identify any hormone relationships by direct addition of some hormones were unsuccessful, so we still do not know which are most directly involved. From the whole-plant phenotypes observed, practically all could potentially be involved. The transcriptomic studies did not shed much light on this aspect, either, since many hormone-controlled genes were altered (Supplementary Table S1).

Our inoculation conditions were strictly controlled in terms of plant developmental stage (1.08). Often in the literature, such strictly controlled inoculation conditions are not followed, so it is not always appropriate to compare results. Regardless of this, occasional plants were inoculated at later developmental stages. In such cases, not all trait alterations reported here were identified. Notably, however, stalk elongation was always halted in UK 1-infected plants a few days after inoculation.

Most of our characterization efforts focused on stalk elongation as a major developmental trait, as UK 1 infection stops elongation. However, the effect of UK 1 on flower development and performance must not be linked to elongation only. The very few flowers obtained from infected plants showed distorted development affecting sepal and petal separation, stamen length, and pollen production. Since so few flowers (many unfertile) were obtained after UK 1 infection, we have not directly analyzed the relationship of this sterility to P3, but some conclusions can be inferred from the work with chimeras. Plants infected with $\mathrm{Ch}$. U(2511-3767)J had elongated stalks and produced a good number of flowers and siliques. This implicates P3 in determining flower fertility. Mostly based on results obtained from transgenic plants, the association of flower developmental defects and associated fertility has been directly assigned by several authors to alterations in miRNA metabolism or in the expression of miRNA-regulated genes, mediated by VSR action (Kasschau et al. 2003; Soitamo et al. 2011). Our results do not directly contradict this miRNA VSR involvement but, again, suggest some hierarchical effect of P3 over HC-Pro action on miRNAs. A direct action of $\mathrm{P} 3$ on miRNAs does not seem likely, since transgenic P3 plants did not display visible developmental defects, regardless of the strain of origin. Further studies are required to assess the precise role of all components in this complex relationship.

The stalk elongation impairment caused by UK 1 infection and the creeping stalk of JPN 1-infected plants suggest effects of both strains on cell-wall metabolism. Both elongation and erection are stalk traits imposed by correct control of cell-wall 
formation (Wolf et al. 2012). Insight into this relationship was obtained by microscopy of early stalk sections. Cell wall-related alterations were, indeed, found and were more marked in UK 1-infected plants. The ectopic cell-wall thickening within vascular vessels and in the intervascular parenchyma is probably responsible for the stalk developmental defects caused by this virus. The overexpression of some genes directly connected to cell-wall transport and metabolism in UK 1-infected plants reinforces this view but, like the miRNA issue discussed above, further investigation is required.

An interesting, hitherto almost unexplored, aspect of gene expression alterations following virus infection was the dynamic time-course analysis to identify the temporal components of the alterations. Partial evidence of very early changes is available (Bazzini et al. 2011), so we performed microarray analyses at two different times, very early and later, when infection was fully established. As described above for virus inoculation, strict control of the developmental stage of the plants to be compared was followed and only plants positive for virus infection were used in the analyses. Unfortunately, the results of the very early sampling did not reveal statistically significant changes in gene expression. Although only plants confirmed as TuMV-infected by RT-PCR were used, there was probably a dilution effect with uninfected tissue. Thus, the temporal analysis was not possible. At the later time, many changes were detected, especially in UK 1-infected plants. The GO terms for biological functions and for cellular components revealed expected changes in metabolic and stress-related genes but, also, development and cell wall-related and chloroplast-related genes. Cell wall-related genes are particularly interesting in light of the abnormalities detected under the light microscope. Chloroplast-related genes are possibly connected to the extensive recruitment of chloroplast membranes taking place during TuMV replication and accumulation (Wei et al. 2010). Finally, the interactome analysis revealed that the most relevant altered genes are probably hubs in the network, in line with a general proposal for many virus-altered genes (Elena and Rodrigo 2012). As in the previous analysis, a cluster related to stress and defense was clearly identified. Another cluster was found, the most connected central genes of which are related to calcium-mediated signaling processes. The possible significance of this cluster and their likely relationships with the altered cell-wall metabolism, transport, and hormone signaling is currently under investigation.

In this paper, we have shown that different strains of the same virus can induce big differences in host development and that there are major drivers of the alterations other than the VSR action on miRNA metabolism. This underlines the limitations of trying to extrapolate and generalize results from transgenic plants overexpressing individual viral genes from one particular strain relative to the complexity and variability of natural viral infections.

\section{MATERIALS AND METHODS}

Plants and virus inoculations.

Arabidopsis plants were grown in controlled chambers and were inoculated with crude sap from virus-infected plants or plasmid DNA, as previously described (Lunello et al. 2007; Sánchez et al. 1998). Growth conditions were $21^{\circ} \mathrm{C}$ (day) and $18^{\circ} \mathrm{C}$ (night) in 16and 8-h cycles. Virus inoculations were performed at stage 1.08 of Arabidopsis development (Boyes et al. 2001).

\section{Light microscopy.}

Sections ( 1 to $2 \mu \mathrm{m}$ thick) of early developing stalks ( $20 \mathrm{dpi}$ ) were stained with toluidine blue $\mathrm{O}$ and were observed with a light microscope under bright field illumination.
JPN 1 FL clone construction and sequencing and infectious viral chimeras.

The strategy previously used for isolate UK 1 (Sánchez et al. 1998) was also followed for isolate JPN 1 . The accession number of the sequence data is KM094174.

The construction of viral chimeras was approached by swapping DNA sequences between the UK 1 infectious clone (p35Tunos) and the (noninfectious) JPN 1 FL clone. All but one of the chimeras were constructed by inserting a JPN 1 DNA sequence into the UK 1 infectious clone. The other was made by inserting a UK 1 sequence into the JPN 1 FL clone. Regions to be swapped were PCR-amplified to include convenient restriction sites (Fig. 5). PCR, restriction digestions, DNA ligations, and E. coli transformations were done following standard molecular biology procedures.

\section{Transgenic Arabidopsis lines.}

Transgenic lines expressing P3 and HC-Pro cistrons were generated and crossed, as described previously by us, for the generation of transgenic Arabidopsis lines for the MP of Oilseed rape mosaic virus (Mansilla et al. 2006). For plant transformation, DNA coding for the proteins of each isolate were amplified from the FL clones and were cloned into the binary vector for transformation, selection, and generation of the transgenic lines.

\section{Microarray analyses, transcriptomic data, and functional analyses.}

RNA was prepared from aerial tissue of inoculated plants, excluding inoculated leaves, and were subjected to microarray analysis (Affymetrix), following the advice and conditions of the external service used (National Center for Biotechnolgy, CSIC, Madrid). Tissue was extracted with phenol and chloroform, was treated with $8 \mathrm{M} \mathrm{LiCl}$, was precipitated with sodium acetate and ethanol, and was cleaned with RNEasy (Qiagen). RNA quality was checked by electrophoresis and Bioanalyzer (Agilent). Data were normalized using the RMA method (Irizarry et al. 2003) for background correction and quantiles for array scaling. The list of differentially expressed genes was obtained by a Limma test (Smyth 2004), with a correction for multiple testing using the false discovery rate (FDR) procedure (Benjamini and Hochberg 1995) (adjusted $P<0.05$ ). The GEPAS tool (Tárraga et al. 2008) was used to perform data normalization and to identify differentially expressed genes. This tool is implemented within the BABELOMICS webserver (Al-Shahrour et al. 2005).

For each list of differentially expressed genes, we looked for significant over-represented biological functions (GO terms levels 3 to 9 ). Statistical significance was evaluated by a Fisher's exact test for $2 \times 2$ contingency tables, with a correction for multiple testing using the FDR procedure (adjusted $P<0.05)$. For the functional analysis, we used the FatiGO tool (Al-Shahrour et al. 2007), implemented in the BABELOMICS webserver. For differentially expressed genes, we also analyzed their direct link to hormone metabolic or signaling processes, using a plant gene-to-hormone database with experimental evidence (Peng et al. 2009).

\section{RT-qPCR.}

Microarray data were validated by RT-qPCR of some selected genes. cDNA was made from the same RNA used for microarray analysis using the kit High Capacity RNA-to-cDNA (Life Technologies), according to the manufacturer's instructions. Primers for RT-qPCR were designed using Primer3Plus (Supplementary Table S2). RT-qPCR was performed in a LightCycler 480 System (Roche), using LightCycler 480 SYBR green I master (Roche), following manufacturer's 
instructions. Cycling conditions for amplifications were as follows. Initial activation step of $95^{\circ} \mathrm{C}$ for $5 \mathrm{~min}$, followed by 45 cycles of $95^{\circ} \mathrm{C}$ for $10 \mathrm{~s}, 60^{\circ} \mathrm{C}$ for $10 \mathrm{~s}$, and $72^{\circ} \mathrm{C}$ for $15 \mathrm{~s}$. Changes in gene expression were determined using the $2^{-\Delta \Delta \mathrm{CT}}$ method (Livak and Schmittgen 2001). Results were expressed as fold change relative to the housekeeping gene Actin 8 (AT1G49240).

\section{Interactomic analysis.}

A recently reported protein-protein interaction network of A. thaliana (At-PPIN) (Arabidopsis Interactome Mapping 2011; Mukhtar et al. 2011) was used to contextualize lists of differentially expressed genes. Analyses of the resulting subnetworks were also performed.

\section{ACKNOWLEDGMENTS}

We thank L. Fernández-Calvino for her help and advice with qPCR protocols, and $\mathrm{C}$. Yuste for her help in improving figure quality. Excellent technical help and support was provided by M. Calvo, L. Zurita, and F. Martínez. This work was mostly funded by Instituto Nacional de Investigación y Tecnología Agraria y Alimentaria (INIA) grants RTA2007-00052-00-00 and Recursos y Teconologías Agrarias (RTA) 2010-00098-00-00 to F. Sánchez and F. Ponz, respectively, and by Spanish Ministry of Economy and Innovation (MINECO) grant BFU2012-30805 to S. F. Elena.

\section{LITERATURE CITED}

Al-Shahrour, F., Minguez, P., Tárraga, J., Medina, I., Alloza, E., Montaner, D., and Dopazo, J. 2007. FatiGO +: A functional profiling tool for genomic data. Integration of functional annotation, regulatory motifs and interaction data with microarray experiments. Nucleic Acids Res. 35:W91-W96.

Al-Shahrour, F., Minguez, P., Vaquerizas, J. M., Conde, L., and Dopazo, J. 2005. BABELOMICS: A suite of web tools for functional annotation and analysis of groups of genes in high-throughput experiments. Nucleic Acids Res. 33:W460-W464.

Arabidopsis Interactome Mapping Consortium 2011. Evidence for network evolution in an Arabidopsis interactome map. Science 333: 601-607.

Bari, R., and Jones, J. D. 2009. Role of plant hormones in plant defence responses. Plant Mol. Biol. 69:473-488.

Bazzini, A. A., Hopp, H. E., Beachy, R. N., and Asurmendi, S. 2007. Infection and coaccumulation of Tobacco mosaic virus proteins alter microRNA levels, correlating with symptom and plant development. Proc. Natl. Acad. Sci. U.S.A. 104:12157-12162.

Bazzini, A. A., Manacorda, C. A., Tohge, T., Conti, G., Rodriguez, M. C., Nunes-Nesi, A., Villanueva, S., Fernie, A. R., Carrari, F., and Asurmendi, S. 2011. Metabolic and miRNA profiling of TMV infected plants reveals biphasic temporal changes. PLoS One 6:e28466.

Benjamini, Y., and Hochberg, Y. 1995. Controlling the false discovery rate: A practical and powerful approach to multiple testing. J. R. Stat. Soc., B 57:289-300.

Boyes, D. C., Zayed, A. M., Ascenzi, R., McCaskill, A. J., Hoffman, N. E., Davis, K. R., and Görlach, J. 2001. Growth stage-based phenotypic analysis of Arabidopsis: A model for high throughput functional genomics in plants. Plant Cell 13:1499-1510.

Chapman, E. J., Prokhnevsky, A. I., Gopinath, K., Dolja, V. V., and Carrington, J. C. 2004. Viral RNA silencing suppressors inhibit the microRNA pathway at an intermediate step. Genes Dev. 18:1179-1186.

Choi, I. R., Stenger, D. C., and French, R. 2000. Multiple interactions among proteins encoded by the mite-transmitted wheat streak mosaic tritimovirus. Virology 267:185-198.

Chung, B. Y., Miller, W. A., Atkins, J. F., and Firth, A. E. 2008. An overlapping essential gene in the Potyviridae. Proc. Natl. Acad. Sci. U.S.A. 105:5897-5902.

Conti, G., Rodriguez, M. C., Manacorda, C. A., and Asurmendi, S. 2012 Transgenic expression of Tobacco mosaic virus capsid and movement proteins modulate plant basal defense and biotic stress responses in Nicotiana tabacum. Mol. Plant-Microbe Interact. 25:1370-1384.

Csorba, T., Kontra, L., and Burgyán, J. 2015. viral silencing suppressors: Tools forged to fine-tune host-pathogen coexistence. Virology 479-480: 85-103.
Cui, X., Wei, T., Chowda-Reddy, R. V., Sun, G., and Wang, A. 2010. The Tobacco etch virus P3 protein forms mobile inclusions via the early secretory pathway and traffics along actin microfilaments. Virology 397 56-63.

Eiamtanasate, S., Juricek, M., and Yap, Y. K. 2007. C-terminal hydrophobic region leads PRSV P3 protein to endoplasmic reticulum. Virus Genes 35:611-617.

Elena, S. F., Carrera, J., and Rodrigo, G. 2011. A systems biology approach to the evolution of plant-virus interactions. Curr. Opin. Plant Biol. 14: 372-377.

Elena, S. F., and Rodrigo, G. 2012. Towards an integrated molecular model of plant-virus interactions. Curr. Opin. Virol. 2:719-724.

Endres, M. W., Gregory, B. D., Gao, Z., Foreman, A. W., Mlotshwa, S., Ge, X., Pruss, G. J., Ecker, J. R., Bowman, L. H., and Vance, V. 2010. Two plant viral suppressors of silencing require the ethylene-inducible host transcription factor RAV2 to block RNA silencing. PLoS Pathog. 6 : e1000729.

Hollings, M., and Brunt, A. A. 1981. Potyvirus group. CMI/AAB Descriptions of Plant Viruses, No. 245. A. J. Gibbs, B. D. Harrison, and A. F. Murant. eds. Commonwealth Mycological Institute, Kew, Surrey, England Nr.

Irizarry, R. A., Hobbs, B., Collin, F., Beazer-Barclay, Y. D., Antonellis, K. J., Scherf, U., and Speed, T. P. 2003. Exploration, normalization, and summaries of high density oligonucleotide array probe level data. Biostatistics 4:249-264.

Jenner, C. E., Sánchez, F., Nettleship, S. B., Foster, G. D., Ponz, F., and Walsh, J. A. 2000. The cylindrical inclusion gene of Turnip mosaic virus encodes a pathogenic determinant to the Brassica resistance gene TuRB01. Mol. Plant-Microbe Interact. 13:1102-1108.

Jenner, C. E., Tomimura, K., Ohshima, K., Hughes, S. L., and Walsh, J. A. 2002. Mutations in Turnip mosaic virus P3 and cylindrical inclusion proteins are separately required to overcome two Brassica napus resistance genes. Virology 300:50-59.

Jenner, C. E., and Walsh, J. A. 1996. Pathotypic variation in Turnip mosaic virus with special reference to European isolates. Plant Pathol. 45 848-856.

Jenner, C. E., Wang, X., Tomimura, K., Ohshima, K., Ponz, F., and Walsh, J. A. 2003. The dual role of the potyvirus P3 protein of Turnip mosaic virus as a symptom and avirulence determinant in brassicas. Mol. PlantMicrobe Interact. 16:777-784.

Kasschau, K. D., Xie, Z., Allen, E., Llave, C., Chapman, E. J., Krizan, K. A., and Carrington, J. C. 2003. P1/HC-Pro, a viral suppressor of RNA silencing, interferes with Arabidopsis development and miRNA unction. Dev. Cell 4:205-217.

Kim, B. M., Suehiro, N., Natsuaki, T., Inukai, T., and Masuta, C. 2010. The P3 protein of Turnip mosaic virus can alone induce hypersensitive response-like cell death in Arabidopsis thaliana carrying TuNI. Mol. Plant-Microbe Interact. 23:144-152.

Lalić, J., and Elena, S. F. 2013. Epistasis between mutations is hostdependent for an RNA virus. Biol. Lett. 9:20120396.

Langenberg, W. G., and Zhang, L. 1997. Immunocytology shows the presence of Tobacco etch virus P3 protein in nuclear inclusions. J. Struct. Biol. 118:243-247.

Leisner, S. M., Turgeon, R., and Howell, S. H. 1993. Effects of host plant development and genetic determinants on the long-distance movement of Cauliflower mosaic virus in Arabidopsis. Plant Cell 5:191-202.

Lin, L., Luo, Z., Yan, F., Lu, Y., Zheng, H., and Chen, J. 2011. Interaction between potyvirus $\mathrm{P} 3$ and ribulose-1,5-bisphosphate carboxylase/oxygenase (RubisCO) of host plants. Virus Genes 43:90-92.

Livak, K. J., and Schmittgen, T. D. 2001. Analysis of relative gene expression data using real-time quantitative PCR and the $2^{-\Delta \Delta \mathrm{Ct}}$ method. Methods 25:402-408

Lough, T. J., and Lucas, W. J. 2006. Integrative plant biology: Role of phloem long-distance macromolecular trafficking. Annu. Rev. Plant Biol. 57:203-232.

Lunello, P., Mansilla, C., Sánchez, F., and Ponz, F. 2007. A developmentally linked, dramatic, and transient loss of virus from roots of Arabidopsis thaliana plants infected by either of two RNA viruses. Mol. Plant-Microbe Interact. 20:1589-1595.

Manacorda, C. A., Mansilla, C., Debat, H. J., Zavallo, D., Sánchez, F., Ponz, F., and Asurmendi, S. 2013. Salicylic acid determines differential senescence produced by two Turnip mosaic virus strains involving reactive oxygen species and early transcriptomic changes. Mol. PlantMicrobe Interact. 26:1486-1498.

Mansilla, C., Aguilar, I., Martínez-Herrera, D., Sánchez, F., and Ponz, F. 2006. Physiological effects of constitutive expression of Oilseed rape mosaic tobamovirus (ORMV) movement protein in Arabidopsis thaliana. Transgenic Res. 15:761-770. 
Martín Martín, A., Cabrera y Poch, H. L., Martínez Herrera, D., and Ponz, F. 1999. Resistances to Turnip mosaic potyvirus in Arabidopsis thaliana. Mol. Plant-Microbe Interact. 12:1016-1021.

Mlotshwa, S., Schauer, S. E., Smith, T. H., Mallory, A. C., Herr, J. M., Jr., Roth, B., Merchant, D. S., Ray, A., Bowman, L. H., and Vance, V. B. 2005. Ectopic DICER-LIKE1 expression in P1/HC-Pro Arabidopsis rescues phenotypic anomalies but not defects in microRNA and silencing pathways. Plant Cell 17:2873-2885.

European Union Effectoromics Consortium, Mukhtar, M. S., Carvunis, A. R., Dreze, M., Epple, P., Steinbrenner, J., Moore, J., Tasan, M., Galli, M., Hao, T., Nishimura, M. T., Pevzner, S. J., Donovan, S. E., Ghamsari, L., Santhanam, B., Romero, V., Poulin, M. M., Gebreab, F., Gutierrez, B. J., Tam, S., Monachello, D., Boxem, M., Harbort, C. J., McDonald, N., Gai, L., Chen, H., He, Y. , Vandenhaute, J., Roth, F. P., Hill, D. E., Ecker, J. R., Vidal, M., Beynon, J., Braun, P., and Dangl, J. L.. 2011. Independently evolved virulence effectors converge onto hubs in a plant immune system network. Science 333:596-601.

Nguyen, H. D., Tomitaka, Y., Ho, S. Y., Duchêne, S., Vetten, H. J., Lesemann, D., Walsh, J. A., Gibbs, A. J., and Ohshima, K. 2013. Turnip mosaic potyvirus probably first spread to Eurasian brassica crops from wild orchids about 1000 years ago. PLoS One 8:e55336.

Ohshima, K., Akaishi, S., Kajiyama, H., Koga, R., and Gibbs, A. J. 2010. Evolutionary trajectory of turnip mosaic virus populations adapting to a new host. J. Gen. Virol. 91:788-801.

Ohshima, K., Tomitaka, Y., Wood, J. T., Minematsu, Y., Kajiyama, H., Tomimura, K., and Gibbs, A. J. 2007. Patterns of recombination in Turnip mosaic virus genomic sequences indicate hotspots of recombination. J. Gen. Virol. 88:298-315.

Ohshima, K., Yamaguchi, Y., Hirota, R., Hamamoto, T., Tomimura, K., Tan, Z., Sano, T., Azuhata, F., Walsh, J. A., Fletcher, J., Chen, J., Gera, A., and Gibbs, A. 2002. Molecular evolution of Turnip mosaic virus: Evidence of host adaptation, genetic recombination and geographical spread. J. Gen. Virol. 83:1511-1521.

Oparka, K. J., Roberts, A. G., Boevink, P., Santa Cruz, S., Roberts, I., Pradel, K. S., Imlau, A., Kotlizky, G., Sauer, N., and Epel, B. 1999. Simple, but not branched, plasmodesmata allow the nonspecific trafficking of proteins in developing tobacco leaves. Cell 97:743-754.

Pallás, V., and García, J. A. 2011. How do plant viruses induce disease? Interactions and interference with host components. J. Gen. Virol. 92: 2691-2705.

Peng, Z. Y., Zhou, X., Li, L., Yu, X., Li, H., Jiang, Z., Cao, G., Bai, M., Wang, X., Jiang, C., Lu, H., Hou, X., Qu, L., Wang, Z., Zuo, J., Fu, X., Su, Z., Li, S., and Guo, H. 2009. Arabidopsis hormone database: A comprehensive genetic and phenotypic information database for plant hormone research in Arabidopsis. Nucleic Acids Res. 37: D975-D982.

Rodríguez-Cerezo, E., Findlay, K., Shaw, J. G., Lomonossoff, G. P., Qiu, S. G., Linstead, P., Shanks, M., and Risco, C. 1997. The coat and cylindrical inclusion proteins of a potyvirus are associated with connections between plant cells. Virology 236:296-306.

Sánchez, F., Martínez-Herrera, D., Aguilar, I., and Ponz, F. 1998. Infectivity of Turnip mosaic potyvirus cDNA clones and transcripts on the systemic host Arabidopsis thaliana and local lesion hosts. Virus Res. 55:207-219.

Sánchez, F., Rodríguez-Mateos, M., Touriño, A., Fresno, J., GómezCampo, C., Jenner, C. E., Walsh, J. A., and Ponz, F. 2007. Identification of new isolates of Turnip mosaic virus that cluster with less common viral strains. Arch. Virol. 152:1061-1068.

Sánchez, F., Wang, X., Jenner, C. E., Walsh, J. A., and Ponz, F. 2003. Strains of Turnip mosaic potyvirus as defined by the molecular analysis of the coat protein gene of the virus. Virus Res. 94:33-43.

Smyth, G. K. 2004. Linear models and empirical bayes methods for assessing differential expression in microarray experiments. Stat. Appl. Genet. Mol. Biol. 3:e3.

Soitamo, A. J., Jada, B., and Lehto, K. 2011. HC-Pro silencing suppressor significantly alters the gene expression profile in tobacco leaves and flowers. BMC Plant Biol. 11:68.

Suehiro, N., Natsuaki, T., Watanabe, T., and Okuda, S. 2004. An important determinant of the ability of Turnip mosaic virus to infect Brassica spp. and/or Raphanus sativus is in its P3 protein. J. Gen. Virol. 85:2087-2098.

Supek, F., Bošnjak, M., Škunca, N., and Šmuc, T. 2011. REVIGO summarizes and visualizes long lists of gene ontology terms. PLoS One 6:e21800.

Tan, Z., Gibbs, A. J., Tomitaka, Y., Sánchez, F., Ponz, F., and Ohshima, K. 2005. Mutations in Turnip mosaic virus genomes that have adapted to Raphanus sativus. J. Gen. Virol. 86:501-510.

Tárraga, J., Medina, I., Carbonell, J., Huerta-Cepas, J., Minguez, P., Alloza, E., Al-Shahrour, F., Vegas-Azcárate, S., Goetz, S., Escobar, P., GarciaGarcia, F., Conesa, A., Montaner, D., and Dopazo, J. 2008. GEPAS, a web-based tool for microarray data analysis and interpretation. Nucleic Acids Res. 36:W308-W314.

Tomimura, K., Gibbs, A. J., Jenner, C. E., Walsh, J. A., and Ohshima, K. 2003. The phylogeny of Turnip mosaic virus: Comparisons of 38 genomic sequences reveal a Eurasian origin and a recent 'emergence' in east Asia. Mol. Ecol. 12:2099-2111.

Touriño, A., Sánchez, F., Fereres, A., and Ponz, F. 2008. High expression of foreign proteins from a biosafe viral vector derived from Turnip mosaic virus. Span. J. Agric. Res. 6:48-58.

Walsh, J. A., and Jenner, C. E. 2002. Turnip mosaic virus and the quest for durable resistance. Mol. Plant Pathol. 3:289-300.

Wei, T., Huang, T. S., McNeil, J., Laliberté, J. F., Hong, J., Nelson, R. S., and Wang, A. 2010. Sequential recruitment of the endoplasmic reticulum and chloroplasts for plant potyvirus replication. J. Virol. 84:799-809.

Wolf, S., Hématy, K., and Höfte, H. 2012. Growth control and cell wall signaling in plants. Annu. Rev. Plant Biol. 63:381-407.

Zilian, E., and Maiss, E. 2011. Detection of plum pox potyviral proteinprotein interactions in planta using an optimized mRFP-based bimolecular fluorescence complementation system. J. Gen. Virol. 92:2711-2723. 